\title{
Changes in urine autofluorescence in ovarian cancer patients
}

\author{
A. BIRKOVA ${ }^{1}$, A. GRESOVA ${ }^{2}$, Z. STEFFEKOVA ${ }^{3}$, V. KRAUS ${ }^{4}$, A. OSTRO ${ }^{5}$, R. TOTH ${ }^{2}$, M. MAREKOVA ${ }^{1}$
}

${ }^{1}$ Pavol Jozef Safarik University in Kosice, Faculty of Medicine, Department of Medical and Clinical Biochemistry, Tr. SNP 1, 04011 Kosice, Slovakia; ${ }^{2}$ Department of Onco-Gyneacology, Eastern Slovak Institute of Cancer a.s., Kosice; ${ }^{3}$ The University of Veterinary Medicine and Pharmacy, Department of Chemistry, Biochemistry and Biophysics, Kosice; ${ }^{4}$ Department of Gyneacology and Obstetrics, Univerzity Hospital of.Pasteur, Kosice; ${ }^{5}$ Pavol Jozef Safarik University in Kosice, Faculty of Medicine, Department of Gyneacology and Obstetrics, Kosice

*Correspondence: maria.marekova@upjs.sk

Received October 17, 2013 / Accepted March 27, 2014

\begin{abstract}
Ovarian cancer is the type of cancer with the highest mortality rate among gynaecologic malignancies. Due to lack of screening tools, this disease is mainly diagnosed at a progressed stage, when it is too late to adequate therapy. Despite many attempts, enough sensitive and specific biomarker was not still uncovered. Fluorescence spectroscopy has proven to be a useful diagnostic tool with high efficiency. Fluorescence detection has three major advantages over other light-based investigation methods: high sensitivity, high speed, and reliability. Biological materials consist of a number of intrinsic fluorescent compounds -autofluorophores, which are associated with cardinal metabolic pathways. It is well known, that cancerous tissue metabolism is altered compared to healthy one, what influence also intrinsic fluorophores composition of bodily fluids. Urine is one of the biological fluids that could be obtained most easily and displays a blue - green fluorescence that can change in case of pathological process. Analysis of urine autofluorescence is non invasive and simple technique. Using fluorescent spectroscopy, ovarian cancer patients and healthy control group were discerned with high significance, so we predict that fluorescence analysis of urine could be a potential means of ovarian cancer screening.
\end{abstract}

Key words: fluorescence, cancer screening, urine, ovarian cancer

Ovarian tumors are concerned a very heterogeneous group of both, epithelial and non-epithelial tumors. Epithelial tumors go developed from the ovarian epithelium (mesothel) and non-epithelial tumors are germ - cell or sex-cord stroma origin, which results in a diversity of suitable diagnostic markers. To overcome this drawback, various tumor markers can be utilized and in combinations can offer better diagnostic results. Even though several tumor markers are already known, the search for an effective screening method is not over. The most used, best described and with dominant importance is carbohydrate antigen CA 125 . The specificity and thus the screening value of CA125 are diminished, however, by the fact that many benign gynaecological conditions, as well as other malignancies, can result in elevated CA 125 levels. Also, while elevated CA 125 is diagnosed in up to $80 \%$ of patients with epithelial ovarian cancer (EOC), it is elevated in only $50-60 \%$ of patients with epithelial ovarian cancer in stage I [1]. The stage-independent sensitivity of serum CA125 as single marker is $70 \%$ at a set specificity of $95 \%$. For the early stage of ovarian cancer, the sensitivity is only $52 \%$ [2] and there is still a subset of ovarian tumors that do not express CA125 [3]. Therefore, new ways of detecting early stage ovary cancer consisting of discovery of a new marker or by combining known markers (panels of markers) and leading to enhancement of sensitivity and specificity are still being sought. Markers incorporated into these analyses look at cancer from different points of view, such as metabolic change, immune response, proliferation signs, overproduction of secretions or hormones, etc. Mostly they are non-specific to any organ or tissue, or their exact function in the human body is not absolutely clear. Overviews of tumor markers associated with ovarian cancer and some tested algorithms are presented in Tables 1 and 2. However, neither of these methods is used in screening or is satisfactory enough for detection of early stage ovarian cancer to improve the prognosis of patients.

Body fluids are valuable biological materials and are more suitable than tissues for screening procedures because they 
Table 1. Tumor markers associated with ovarian cancer (HE 4 - human epididymis protein 4, SMRP - soluble mesothelin-related peptide, GTCT - granulose-theca cell tumors, OGCT - ovarian germ cell tumors)

\begin{tabular}{|c|c|c|c|c|c|c|}
\hline Marker & $\begin{array}{l}\text { Sensitivity } \\
\%\end{array}$ & Specificity \% & EOC expression & Non-EOC expression & Comment & Ref. \\
\hline CA 125 & $\begin{array}{c}70 ; \\
\text { for early stage } 52\end{array}$ & 95 & + & \pm & $\begin{array}{l}\text { elevated in benign conditions and } \\
\text { other malignancies }\end{array}$ & 2 \\
\hline HE4 & 76.5 & 95 & + & & less in benign condition & \\
\hline SMRP & 53.7 & 95 & & & & \\
\hline Total inhibin & $\begin{array}{c}93 / 94 \\
\text { (serous/mucinous) } \\
\end{array}$ & & + & & & 4 \\
\hline Total inhibin & & & + & + for GTCT & import in menopausal women & 5 \\
\hline Inhibin A & 67 & 100 & & & & 6 \\
\hline Inhibin B & 89 & 100 & & & correlates with malignant disease & \\
\hline B7-H4 & & & & & $\begin{array}{l}+ \text { in } 1 / 2 \text { of early cancer and } 2 / 3 \text { of } \\
\text { advanced stage patients }\end{array}$ & 7 \\
\hline$\alpha \mathrm{FP}$ & & & & & & 8 \\
\hline ßhCG & & & & + for OGCT & + only in advanced stage & 9 \\
\hline LDH & & & & & & \\
\hline $\begin{array}{l}\text { Oestrogen } \\
\text { Androstenedione }\end{array}$ & & & & + for GTCT & & 10 \\
\hline
\end{tabular}

Table 2. Combination of CA125 biomarker with others

\begin{tabular}{|c|c|c|c|c|}
\hline Additional biomarker & $\begin{array}{l}\text { Sensitivity } \\
\%\end{array}$ & $\begin{array}{l}\text { Specificity } \\
\%\end{array}$ & Comment & Ref. \\
\hline HE4 & 92.3 & 75 & post-menopausal & 11 \\
\hline HE4 & 76.5 & 74.8 & pre-menopausal & \\
\hline \multirow[t]{2}{*}{ HE4 (ROMA, logaritmic values) } & 94.3 & 75 & depending on menopausal state & 12 \\
\hline & & & $\begin{array}{l}\text { decreased results after the inclusion of border-line } \\
\text { tumors, metastatic tumors, non-EOC }\end{array}$ & 13 \\
\hline SMRP & 56.8 & 95 & & 2 \\
\hline Total inhibin & $\begin{array}{c}\text { 99/95 } \\
\text { (serous/mucinous) }\end{array}$ & & & 4 \\
\hline B7-H4 & 65 & 97 & $\begin{array}{l}\text { suitable for early stage, elevated in both benign } \\
\text { and malignant }\end{array}$ & 14 \\
\hline $\begin{array}{l}\text { C-reactive protein, serum amyloid } A \text {, interleukin } \\
6 \text {, interleukin } 8\end{array}$ & 94 & 91 & & 15 \\
\hline $\begin{array}{l}\text { Leptin, prolactin, osteopontin, insulin-like } \\
\text { growth factor II and macrophage migration } \\
\text { inhibitory factor }\end{array}$ & 95.3 & 98.7 & positive predictive value $6.5 \%$ & 16 \\
\hline
\end{tabular}

are less invasive. Their exact composition is not yet known and is still being studied. Proteomics and the use of robust analytical techniques (mass spectroscopy) to explore biological fluids such as serum, urine or ascites for possible markers offer new screening possibilities for early diagnostic of ovarian cancer. The comprehensive ascites proteome in advanced ovarian cancer has already been published and includes a list of 80 candidate markers [17]. Early attempt at profiling lowmolecular-weight serum proteins has yielded surprisingly good results - sensitivity of $100 \%$, specificity of $95 \%$ and a positive predictive value of $94 \%$ [18]. Recent studies have continued to deliver similar results, with sensitivity, specificity and positive predictive value all above the $95 \%$ threshold [ 19 , 20]. Proteomics also seems to be useful in the classification of information on specific ovarian cancer subtypes, which can be used to tailor pre-surgical therapy [21]. The study of genes and regulatory proteins (genomics and proteomics) has focused mainly on diagnostics, but the study of small molecules must also not be forgotten and should be placed on the same level of importance. "While genomic or proteomic analysis cannot give any evidence of stress even if the person turns blue, metabolomics will indicate dramatic changes" 
[22]. Fluorescence measurement of biological materials is a very sensitive, simple executable and cost-effective tool with great potential for clinical diagnostics. The use of fluorescent spectroscopy capable of studying molecular interaction could become a very useful method, even if is not specific to particular fluorophores.

With the aim of decreasing mortality in patients with ovarian cancer, management of such patients should be multidisciplinary. Team of professionals from different medical science disciplines should participate in both early detection (screening, markers, imaging methods) and multimodal therapy (surgical, oncological). Without a solid understanding of the origin of cancer, it becomes difficult to specify a clear strategy for effective management. For most genes the mutation rate is low, but cancer cells express many different types and kinds of mutations. New insights into cancer as a primarily metabolic disease will result in novel approaches to cancer management and prevention. Autofluorescencebased optical imaging technologies could be an inexpensive step forward in supporting the development in vivo screening for cancer diagnoses. The native fluorescence or autofluorescence of some molecules can provide useful information about the metabolism of normal cells. It is known, that endogenous fluorescence from aromatic amino acids, certain proteins as well as coenzymes in tissues, can be altered by carcinogenesis.

Most studies using the high sensitivity of fluorescence for cancer detection are focused on tumor tissue or cell materials and declare high diagnostic sensitivity and specificity. Screening suitability and cancer risk prediction are also mentioned often. Although changes in metabolism during pathological states can endure well beyond morphological changes, results from fluorescence measurements are almost always related to histological diagnoses in order to confirm the accuracy of the assumption. For screening, procedures they are as simple as possible and are the most suitable. Despite their suitability for screening and their less invasive collection, biological fluids are rarely used for similar experimental purposes. Recently, Masilamani et al. [23], in their study using urine for early cancer detection, described the case of a patient with lung cancer, for whom four biological materials (lung cancer tumor tissue, plasma, urine and pleural effusion) were examined, with the result, that the fluorescence spectrum of the urine was very similar to that of the tumor tissue. In addition, autofluorescence of urine was reported in conjunction to renal diseases [24] and urinary tract infection [25]. To our knowledge, only Lu et al. [26] has described urine autofluorescence as potential diagnostic tool for ovarian cancer patients, but without providing information about the number of tested groups of healthy and diseased patients.

The present study is focused on the applicability of one of most available biological materials - urine - for serious disease diagnostics in regard to the lack of a satisfactory screening method - for ovarian cancer detection.

\section{Materials and methods}

For the experiment, groups of patients were created as follows: healthy women without cancer anamnesis $(\mathrm{N}=36$, age $22-65$, average $35.7 \pm 9.7$ ), patients with a benign ovarian tumor $(\mathrm{N}=16$, age $27-86$, average $54.6 \pm 17.8)$ and patients with malignant ovarian cancer $(\mathrm{N}=21$, age $33-84$, average $59.9 \pm 14.4)$. The group of patients with ovarian cancer also included border-line tumors $(\mathrm{N}=3)$. Healthy women filled in the questionnaire about their age, health status and anamnestic information. Information about the benign or malignant origin of tumors was based on the results of the final histopathological examination after surgery. All patients signed the informed consent.

Morning urine samples from fasting subjects were withdrawn from middle stream and frozen at $-18^{\circ} \mathrm{C}$ until. Thawed urine samples were centrifuged for 10 minutes at $3000 \mathrm{rpm}$. The autofluorescence of undiluted urines was measured at room temperature, using a Luminescence Spectrophotometer Perkin Elmer LS 55 (USA) in a $10 \mathrm{~mm}$ quartz cuvette. From every sample we measured synchronous spectra with $\Delta \Lambda 30 \mathrm{~nm}$ in the range $250-545$, step $0,5 \mathrm{~nm}$, excitation/ emission slits $5 / 5 \mathrm{~nm}$, and a scan speed of $1200 \mathrm{~nm} / \mathrm{min}$. For better comparison and discrimination of groups we used both original and normalized spectra. A Student's T-test was used to calculate the statistical significance.

\section{Results}

The fluorescence spectra of urines are the function of many overlapping chromophores present in the sample. The synchronous spectrum $(\Delta \Lambda 30 \mathrm{~nm})$ of undiluted urine is characteristic with 2 peaks (Figure 1). The maximum of the first peak may vary over a wide range of wavelengths from $340-420 \mathrm{~nm}$. The second peak's maximum is typical and repeating at $480 \mathrm{~nm}$. Due to the wide range of the wavelength, we can only speculate about what is hidden in the first peak, but the second peak is most likely given by the fluorescence of riboflavin and its derivatives.

The intensity of fluorescence in both areas mentioned above highly varies visually in all tested groups. Often (in all groups) a peak was present in various parts of the spectra which exceeded the detection limit and increased the dispersion of the fluorescence emission values. The standard deviation sometimes exceeded the average value. When matching the average spectra, some differences are seen, but statistical analysis differs from visual evaluation. When comparing the values of fluorescence intensity statistically in the whole range of spectra $(250-545 \mathrm{~nm}$, step $0.5 \mathrm{~nm})$ between all three examined groups, no significant differences were found between the group of healthy patients and those with a benign tumor, however, a few significant differences were found between the group of patients with malignant tumors and both the healthy women and those with a benign tumor. 

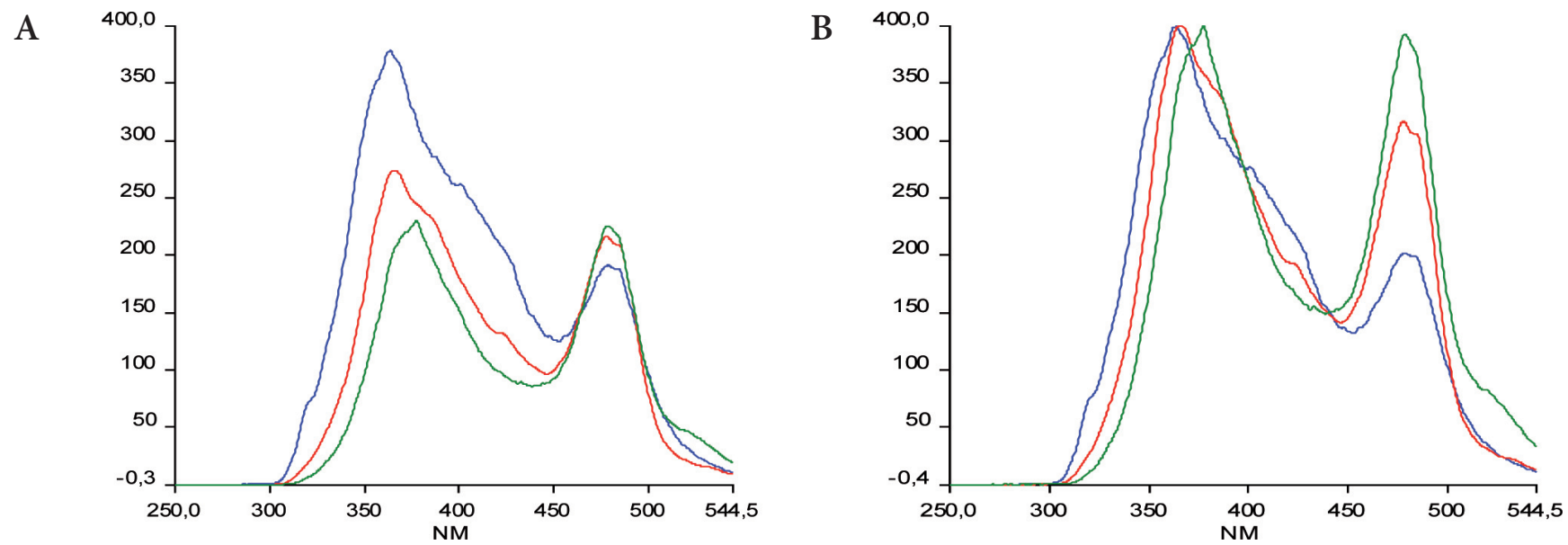

Figure 1. Average synchronous spectra of healthy control group (red lines), patients with benign tumors (blue) and patients with a malignant tumor (green). A) untouched synchronous spectra; B) normalized synchronous spectra.

The first difference was between healthy women and women with a malignant ovarian cancer at $312-317 \mathrm{~nm}$ (Figure 2A), with significance around $p=0.04(0.039-0.048)$. The second difference was between groups with malignant and benign tumors, but not when compared with the healthy women in the range at $325-360(\mathrm{p}=0.015-0.049)$. This spectral difference was most expressed at $350 \mathrm{~nm}$ (Figure 2B). The third difference appeared in the range $422-430 \mathrm{~nm}(\mathrm{p}=0.030$
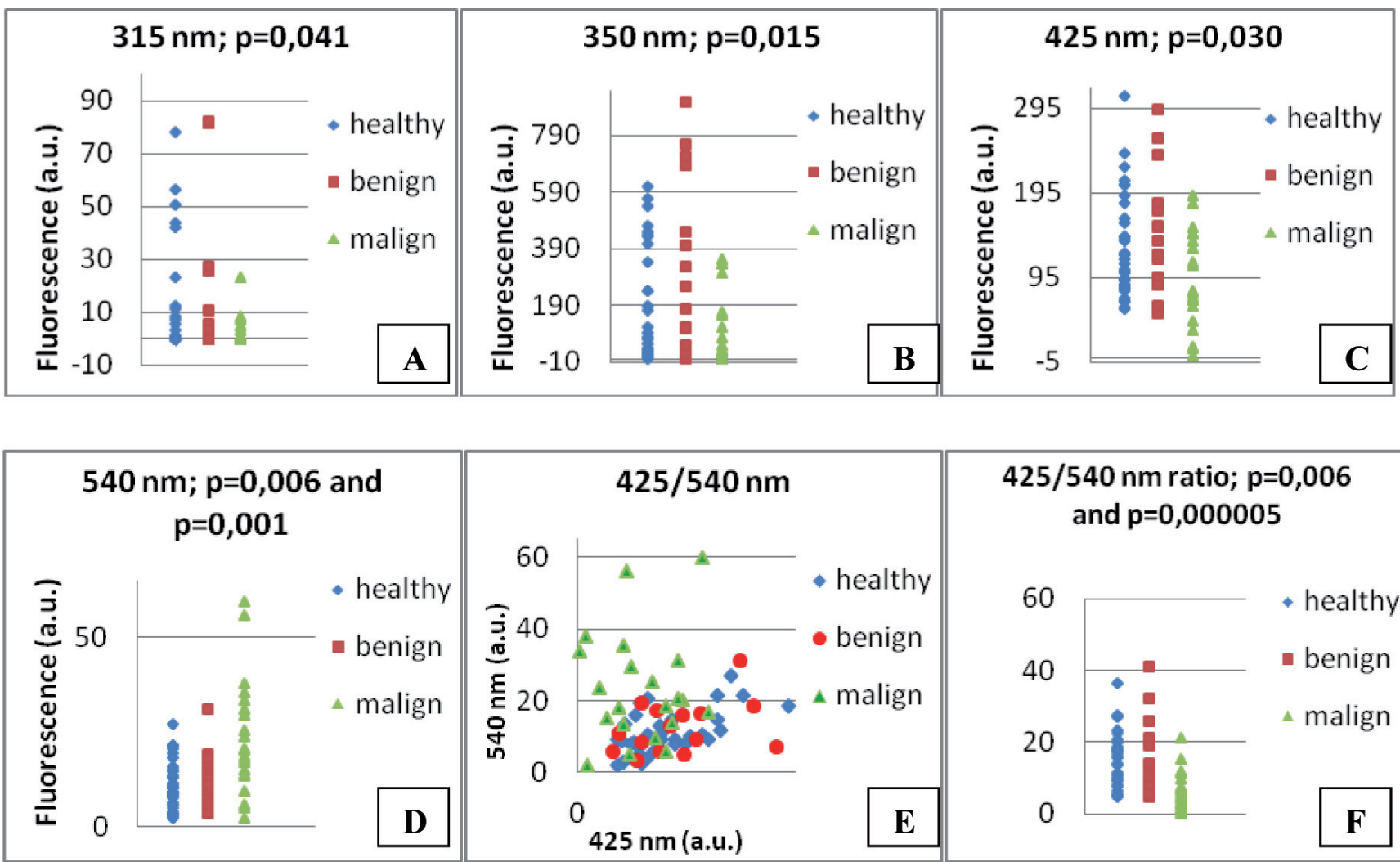

$425 / 540 \mathrm{~nm}$ ratio; $p=0,006$ and $\mathrm{p}=0,000005$

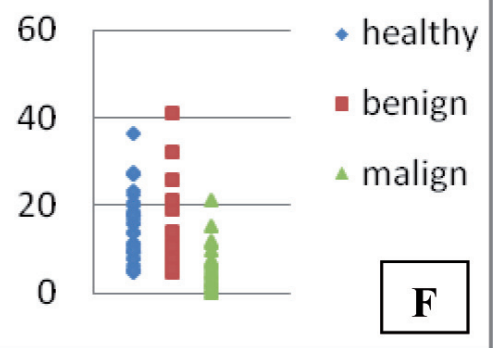

Figure 2. Fluorescence intensities at 315 (A), 350 (B), 425 (C) and $540 \mathrm{~nm}$ (D), the relation between 425 and $540 \mathrm{~nm}(\mathrm{E})$ and the ratio $425 / 540 \mathrm{~nm}$ values $(\mathrm{F})$ 
-0.048 ) between the healthy group and the malignant ovarian cancer patients (Figure 2C). The spectra from women suffering from ovarian cancer differed with the highest significance in the part of spectra from $505-545 \mathrm{~nm}$. The significant value when comparing healthy vs. malign is $\mathrm{p}=0.011-0.047$ in the range $505-509 \mathrm{~nm}$ and $\mathrm{p}=0.001-0.009$ in the range 510 $-545 \mathrm{~nm}$. When comparing the benign vs. the malign group, significance was $p=0.006-0.049$ in the range $525-545 \mathrm{~nm}$. For both, the healthy women and those with benign tumors when compared with those having malign tumors the most striking distinction appeared at $540 \mathrm{~nm}$ (Figure 2D). The difference between the groups can be improved by calculating the $425 / 540 \mathrm{~nm}$ ratio with values $\mathrm{p}=0.006$ for benign vs. malign and $p=0.000005$ for healthy vs. patients with malign ovarian cancer (Figures $2 \mathrm{E}$ and $2 \mathrm{~F}$ ). The results of statistical analysis are shown in Table 3.

\section{Discussion}

Until now many markers suitable for ovarian cancer have been reported, but with no satisfaction. There is great interest in decreasing the mortality of ovarian cancer and finding any marker suitable for early diagnostics, the best being when the disease is still in its curative stage (I-II). Only a few pilot studies have described and evaluated the differentiation efficacy between autofluorescence of ovarian tissues under normal, benign and malignant conditions. Both, the sensitivity and specificity they reported, are high and produce a real-time diagnosis. Kamath et al. used pulsed laser excitation at $325 \mathrm{~nm}$ to obtain fluorescence spectra in the range from $350-600 \mathrm{~nm}$ to discriminate 34 normal, 33 benign and 30 malignant ovarian tissues from 22 subjects, with $90.9 \%$ sensitivity and $100 \%$ specificity [27]. Also, Renkoski et al. reported similar experimental parameters ( 30 patients, excitation at $325 \mathrm{~nm}$ and 8 emission bands from $400-640 \mathrm{~nm}$ ) to obtain fluorescence spectra, and their ability to discriminate ovarian cancer from normal tissue was with $100 \%$ sensitivity and $51 \%$ specificity [28]. George et al. carried out a study with a wider excita- tion (270-550 $\mathrm{nm})$ and also emission (290-700 $\mathrm{nm})$ range. The number of patients was higher (49 patients undergoing oophorectomy) and when classifying malignant versus others samples, they achieved $88 \%$ sensitivity and $93 \%$ specificity. They described an increased performance of classifying cancer when the normal group excludes benign neoplasm and endometriosis samples [29]. All of the mentioned studies used sophisticated mathematical analysis for classification of the sample groups. McAlpine et al. reported changes of fallopian tube epithelium autofluorescence detected in tissues ex vivo in 47 patients with ovarian cancer or a history of hereditary breast-ovarian cancer, with a calculated sensitivity of $73 \%$ and $83 \%$ specificity. The results were better $(87.5 \%$ sensitivity and $92 \%$ specificity) when the values in a subgroup that excluded non-serous histology were determined [30].

Many publications $[23,31,32]$ report on the significant changes of flavines and NADH in tissues or body fluids in patients with oncologic disease. In our experiments with undiluted urine autofluorescence, we detected a peak at $540 \mathrm{~nm}$, which was the most important feature in distinguishing with high significance the group of healthy women or those with benign tumors from those with malignant tumors. Some earlier reports exist describing a peak at a similar or the same wavelength in cancer. Dramićanin et al. (2006) similarly described in mammary cancer tissue an unidentified peak in synchronous spectra with the same wavelength difference as we found. Some authors attribute this wavelength specifically to excess flavine fluorescence (ex/em 450/520 - $530 \mathrm{~nm}$ ). However, in our conditions with synchronous spectra of $\Delta \Lambda 30 \mathrm{~nm}$, flavines we have a peak at $478-480 \mathrm{~nm}$. As the increased fluorescence at $540 \mathrm{~nm}$ rather imitated the tail of the flavine peak or the new peak formation, not increased fluorescence at $478-480 \mathrm{~nm}$, and we evaluated this wavelength as very variable part of spectrum in both healthy and diseased patients, we think that flavines alone do not account for the spectral difference when comparing healthy patients with those having cancer and anticipate another reason [33]. Masilamani et al. also used the synchronous spectra $(\Delta \lambda 70 \mathrm{~nm})$

Table 3. Values of fluorescence intensity at $315,350,425,540 \mathrm{~nm}$, and the calculated ratio $425 / 540 \mathrm{~nm}$

\begin{tabular}{|c|c|c|c|c|c|c|}
\hline Patient & Parameter & $315 \mathrm{~nm}$ (a.u.) & $350 \mathrm{~nm}$ (a.u.) & $425 \mathrm{~nm}$ (a.u.) & $540 \mathrm{~nm}$ (a.u.) & $425 / 540 \mathrm{~nm}$ \\
\hline \multirow[t]{2}{*}{ Healthy } & Average & 9.8 & 170.5 & 129.4 & 10.7 & 14.9 \\
\hline & SD & 19.6 & 194.6 & 59.9 & 6.1 & 7.6 \\
\hline \multirow[t]{3}{*}{ Benign } & Average & 40.9 & 313.4 & 201.4 & 12.5 & 15.32 \\
\hline & SD & 103.5 & 305.7 & 223.9 & 7.2 & 10.6 \\
\hline & $\begin{array}{c}\text { T-test } \\
\text { healthy vs. benign }\end{array}$ & 0.25 & 0.10 & 0.22 & 0.39 & 0.90 \\
\hline \multirow[t]{4}{*}{ Malign } & Average & 2.4 & 97.4 & 93.9 & 23.5 & 6.1 \\
\hline & $\mathrm{SD}$ & 5.4 & 127.3 & 56.2 & 15.1 & 5.4 \\
\hline & $\begin{array}{l}\text { T-test } \\
\text { healthy vs. malign }\end{array}$ & 0.04 & 0.096 & 0.030 & 0.001 & 0.000005 \\
\hline & $\begin{array}{c}\text { T-test } \\
\text { benign vs. malign }\end{array}$ & 0.16 & 0.016 & 0.079 & 0.007 & 0.006 \\
\hline
\end{tabular}


reported in patients with cancer, with a typical red shift of the peak of $20 \mathrm{~nm}$ from 510 to $530 \mathrm{~nm}$. They found an increased peak at $530 \mathrm{~nm}$ and a decreased peak at $515 \mathrm{~nm}$, which the authors attributed to excessive concentration of flavines leading to self-quenching of original $515 \mathrm{~nm}$ peak. However, there is no self quenching of excess of flavines concentration in urine at our conditions (data not presented), and we detected an increased fluorescence shifted $60 \mathrm{~nm}$ from the flavines peak (from 480 to $540 \mathrm{~nm}$ ), we therefore think that another change is responsible for the increasing of fluorescence at $540 \mathrm{~nm}$, as do Masilamani et al. [23]. To our knowledge, Lu et al. were first who tested urine in ovarian cancer with a similar finding who considered the interplay of coproporphyrin, riboflavin and p-hydroxyphenol derivatives existing in urine [34]. Zvarík et al. used excitation-emission matrices of undiluted urine in ovarian cancer screening. They revealed significant differences $(\mathrm{p}<0.001)$ between ovarian cancer patients and healthy donors at the emission wavelength from $400 \mathrm{~nm}$ to $460 \mathrm{~nm}$ when excited at $310-390 \mathrm{~nm}$ [35]. Norgaard et al. highlighted the importance of the fact, that results from fluorescent fingerprints should be interpreted as "un block", not only by considering one or a few concrete fluorophores, but also in relation to the environment in which the fluorescent compounds exist [36].

As urine is a very complex fluid, and since ovarian cancer is specific in its heterogeneous origin, we are not surprised that few changes in urine spectra were found in diseased patients compared with healthy women. There are many fluorophores present in urine which may possibly be associated with cancer, like molecules linked to oxidative stress and aging or immune response, for instance, or advanced glycation end-products, pterines, various tryptophan derivatives or certain proteins like collagen or elastin. Many of them are multifunctional in human organism and can accompany different health situations, not only cancer disease. In addition, we must not forget that previously unknown substances could also be present in urine in such a condition. Compounds responsible for changes in fluorescent spectra can be estimated only be the fluorescent fingerprints of urine, but this can be a very useful tool for detection of changes between groups, as our results show.

We evaluate as very interesting the area around $350 \mathrm{~nm}$, where statistics show a significant difference between benign vs. malign groups, but not between healthy vs. malign or benign vs. healthy. This could be caused by a combination of the already mentioned incidental peaks and the small patient number, which is the greatest disadvantage of this study. Another is the fact, that the group with malignant ovarian cancer consisted mostly of women in stage III $(\mathrm{N}=5)$ and IV $(\mathrm{N}=9)$ and in three patients the stage could not be established. Only one patient was in stage I and three patients were with borderline tumors. If the fluorescent fingerprints of urine can help with screening for ovarian cancer, it is necessary to test more patients with ovarian cancer in the early stage, which is not an easy task, as the diagnostic capacity at this early stage are very poor. Also, the fact that we often detected unidentified peak excesses and tested such a small number of patients could have a significant impact on the results of the statistical analysis, it is therefore desirable to exclude from analysis certain factors on the fluorescence of urine, such as diet or pharmacotherapy influence, by advanced patient preparation and guidance before urine collection.

\section{Conclusion}

This small study was oriented on possible urine utilization as a biological material suitable as non-invasive screening procedure for ovarian cancer by a cost - effective and very simply executable autofluorescence measurement. Fluorescence is a very sensitive and suitable method for detecting unexpected changes, which can be of various origin. Significant or highly significant differences were detected in several areas of the spectrum between patients with malignant ovarian cancer and healthy women (at 315, 425 and $540 \mathrm{~nm}$ ) or those with benign histology ( 350 and $540 \mathrm{~nm}$ ). The statistical analysis of fluorescence intensities also showed no difference between the healthy group and women with benign ovarian tumors in the entire measured spectrum range. In further research there is a need to solve some problems, like enlarging the tested sample number with an emphasis on the early stage of ovarian cancer or better preparation of patients before urine collection. Based on results obtained in these measurements we can say there is some potential and perspective to using the fluorescent fingerprints of urine as a helpful method for ovarian cancer screening.

Acknowledgements: This study was supported by the grant VEGA $1 / 0402 / 10$

\section{References}

[1] WOOLAS RP, XU FJ, JACOBS IJ, YU YH, DALY L et al. Elevation of multiple serum markers in patients with stage I ovarian cancer. J Natl Cancer Inst 1993; 85: 1748-1751. http://dx.doi.org/10.1093/jnci/85.21.1748

[2] MOORE RG, BROWN AK, MILLER MC, SKATES S, ALLARD WJ et al. The use of multiple novel tumor biomarkers for the detection of ovarian carcinoma in patients with a pelvic mass. Gynecol Oncol 2008; 108: 402-408. http://dx.doi. org/10.1016/j.ygyno.2007.10.017

[3] SHAH CA, LOWE KA, PALEY P, WALLACE E, ANDERSON GL et al. Influence of ovarian cancer risk status on the diagnostic performance of the serum biomarkers mesothelin, HE4, and CA125. Cancer Epidemiol Biomarkers Prev 2009; 18: 1365-1372. http://dx.doi.org/10.1158/1055-9965.EPI-081034

[4] TSIGKOU A, MARRELLI D, REIS FM, LUISI S, SILVA-FILHO AL et al. Total inhibin is a potential serum marker for epithelial ovarian cancer. J Clin Endocrinol Metab 2007; 92: 2526-2531. http://dx.doi.org/10.1210/jc.2007-0235 
[5] ROBERTSON D, BURGER HG, FULLER PJ Inhibin/activin and ovarian cancer. Endocr Relat Cancer 2004; 11: 35-49. http://dx.doi.org/10.1677/erc.0.0110035

[6] MOM CH, ENGELEN MJ, WILLEMSE PH, GIETEMA JA, TEN HOOR KA et al. Granulosa cell tumors of the ovary: the clinical value of serum inhibin A and B levels in a large single center cohort. Gynecol Oncol 2007; 105: 365-372. http://dx.doi.org/10.1016/j.ygyno.2006.12.034

[7] SIMON I, LIU Y, KRALL KL, URBAN N, WOLFERT RL et al. Evaluation of the novel serum markers B7-H4, Spondin 2, and DcR3 for diagnosis and early detection of ovarian cancer. Gynecol Oncol 2007; 106: 112-118. http://dx.doi.org/10.1016/ j.ygyno.2007.03.007

[8] MURUGAESU N, SCHMID P, DANCEY G, AGARWAL R, HOLDEN L et al. Malignant ovarian germ cell tumors: identification of novel prognostic markers and long-term outcome after multimodality treatment. J Clin Oncol 2006; 24: 4862-4866. http://dx.doi.org/10.1200/JCO.2006.06.2489

[9] PERKINS GL, SLATER ED, SANDERS GK, PRICHARD JG Serum tumor markers. Am Fam Physician 2003; 68: 1075-1082.

[10] KOUKOURAKIS GV, KOULOULIAS VE, KOUKOURAKIS MJ, ZACHARIAS GA, PAPADIMITRIOU C et al. Granulosa cell tumor of the ovary: tumor review. Integr Cancer Ther 2008; 7: 204-215. http://dx.doi.org/10.1177/ 1534735408322845

[11] MOORE RG, MCMEEKIN DS, BROWN AK, DISILVESTRO P, MILLER MC et al. A novel multiple marker bioassay utilizing HE4 and CA125 for the prediction of ovarian cancer in patients with a pelvic mass. Gynecol Oncol 2009; 112: 40-46. http://dx.doi.org/10.1016/j.ygyno.2008.08.031

[12] MOORE RG, JABRE-RAUGHLEY M, BROWN AK, ROBISON KM, MILLER MC et al. Comparison of a novel multiple marker assay vs the Risk of Malignancy Index for the prediction of epithelial ovarian cancer in patients with a pelvic mass. Am J Obstet Gynecol 2010; 203: 228.e221-228.e226.

[13] VAN GORP T, CADRON I, DESPIERRE E, DAEMEN A, LEUNEN K et al. HE4 and CA125 as a diagnostic test in ovarian cancer: prospective validation of the Risk of Ovarian Malignancy Algorithm. Br J Cancer 2011; 104: 863-870. http://dx.doi.org/10.1038/sj.bjc.6606092

[14] SIMON I, KATSAROS D, RIGAULT DE LA LONGRAIS I, MASSOBRIO M, SCORILAS A et al. B7-H4 is over-expressed in early-stage ovarian cancer and is independent of CA125 expression. Gynecol Oncol 2007; 106: 334-341. http://dx.doi. org/10.1016/j.ygyno.2007.03.035

[15] EDGELL T, MARTIN-ROUSSETY G, BARKER G, AUTELITANO DJ, ALLEN D et al. Phase II biomarker trial of a multimarker diagnostic for ovarian cancer. J Clin Oncol 2010; 136: 1079-1088.

[16] VISINTIN I, FENG Z, LONGTON G, WARD DC, ALVERO BA, LAI Y et al. Diagnostic markers for early detection of ovarian cancer. Clin Cancer Res 2008; 14: 1065-1072. http://dx.doi. org/10.1158/1078-0432.CCR-07-1569

[17] GORTZAK-UZAN L, IGNATCHENKO A et al. A proteome resource of ovarian cancer ascites: integrated proteomic and bioinformatic analyses to identify putative biomarkers. J
Proteome Res 2008; 7: 339-351. http://dx.doi.org/10.1021/ pr0703223

[18] PETRICOIN EF, ARDEKANI AM, HITT BA, LEVINE PJ, FUSARO VA et al. Use of proteomic patterns in serum to identify ovarian cancer. Lancet 2002; 359: 572-577. http:// dx.doi.org/10.1016/S0140-6736(02)07746-2

[19] MONTAZERY-KORDY H, MIRAN-BAYGI M, MORADI M. A data-mining approach to biomarker identification from protein profiles using discrete stationary wavelet transform. Journal of Zhejiang University - Science B 2008; 9: 863-870. http://dx.doi.org/10.1631/jzus.B0820163

[20] HONG Y, WANG X, SHEN D, ZENG S Discrimination analysis of mass spectrometry proteomics for ovarian cancer detection1. Acta Pharmacol. Sin 2008; 29: 1240-1246. http:// dx.doi.org/10.1111/j.1745-7254.2008.00861.x

[21] WU B, ABBOTT T, FISHMAN D, MCMURRAY W, MOR G et al. Ovarian Cancer Classification based on Mass Spectrometry Analysis of Sera. Cancer Inform 2007; 2: 123-132.

[22] BLOW N Metabolomics: biochemistry's new look. Nature 2008; 455: 697-700. http://dx.doi.org/10.1038/455697a

[23] MASILAMANI V, VIJMASI T, AL SALHI M, GOVINDARAJ $\mathrm{K}$, VIJAYA-RAGHAVAN AP et al. Cancer detection by native fluorescence of urine. J Biomed Opt 2010; 15: 057003-1057003-9. http://dx.doi.org/10.1117/1.3486553

[24] DUBAYOVA K, KUSNIR J, PODRACKA L Diagnostic monitoring of urine by means of synchronous spectrum. J Biochem Biophys Methods 2003; 55: 111-119. http://dx.doi. org/10.1016/S0165-022X(03)00031-9

[25] ANWER AG, PERINCHERY MS, EWA MG, SUBRAMANYAM V Distinctive autofluorescence of urine samples from individuals with bacteriuria compared with normals Clin Chim Acta 2009; 401: 73-5. http://dx.doi.org/10.1016/ j.cca.2008.11.021

[26] LU J, GAO S, YANG Y, LU X, CHEN G Study on characteristic intrinsic fluorescence spectra of urine from ovarian cancer patients. Optics in Health Care and Biomedical Optics III, Proc of SPIE 2007; 6826: 68262O-1-68262O-7. http://dx.doi. org/10.1117/12.756498

[27] KAMATH SD, BHAT RA, RAY S, MAHATO KK Autofluorescence of normal, benign, and malignant ovarian tissues: a pilot study. Photomed Laser Surg 2009; 27: 325-35. http:// dx.doi.org/10.1089/pho.2008.2261

[28] RENKOSKITE, HATCH KD, UTZINGER U Wide-field spectral imaging of human ovary autofluorescence and oncologic diagnosis via previously collected probe data. J Biomed Opt 2012; 17: 036003. http://dx.doi.org/10.1117/1.JBO.17.3.036003

[29] GEORGE R, MICHAELIDES M, BREWER MA, UTZINGER $\mathrm{U}$. Parallel factor analysis of ovarian autofluorescence as a cancer diagnostic. Lasers Surg Med 2012; 44: 282-95. http:// dx.doi.org/10.1002/lsm.22014

[30] MCALPINE JN, EL HALLANI S, LAM SF, KALLOGER SE, LUK $M$ et al. Autofluorescence imaging can identify preinvasive or clinically occult lesions in fallopian tube epithelium: a promising step towards screening and early detection. Gynecol Oncol 201; 120: 385-92.

[31] KALA S, PANTOLA CH, AGARWAL A, PRADHAN A, THAKUR S Optical Spectroscopy: A Promising Diagnos- 
tic Tool for Breast Lesions. J Clin Diagnostic Res 2011; 5: 1574-1577.

[32] CONKLIN MW, PROVENZANO PP, ELICEIRI KW, SULLIVAN R, KEELY PJ Fluorescence lifetime imaging of endogenous fluorophores in histopathology sections reveals differences between normal and tumor epithelium in carcinoma in situ of the breast. Cell Biochem Biophys 2009; 53: 145-57. http://dx.doi.org/10.1007/s12013-009-9046-7

[33] DRAMICANIN T Discrimination Between Normal and Malignant Breast Tissues by Synchronous Luminescence Spectroscopy. Acta Chim Slov 2006; 53: 444-449.

[34] LU J, GAO S, YANG Y, LU X, CHEN G Study on characteristic intrinsic fluorescence spectra of urine from ovarian cancer patients. Optics in Health Care and Biomedical Optics III, Proc of SPIE 2007; 6826: 68262O-1-68262O-7. http://dx.doi. org/10.1117/12.756498

[35] ZVARIK M, MARTINICKY D, HUNAKOVA I, LAJDOVA I, SIKUROVA L Fluorescence characteristic of human urine from normal individuals and ovarian cancer patients. Neoplasma 2013; 5: 533-537. http://dx.doi.org/10.4149/ neo $2013 \quad 069$

[36] NORGAARD L et al. Fluorescence spectroscopy and chemometrics for classification of breast cancer samples - a feasibility study using extended canonical variates analysis. J. Chemometrics 2007; 21: 451-458. http://dx.doi.org/10.1002/ cem.1042 